University of Nebraska - Lincoln

DigitalCommons@University of Nebraska - Lincoln

West Central Research and Extension Center, North Platte

2020

\title{
Diurnal and Seasonal Activity Patterns of Drosophilid Species (Diptera: Drosophilidae) Present in Blackberry Agroecosystems With a Focus on Spotted-Wing Drosophila
}

Katharine A. Swoboda-Bhattarai

Hannah Burrack

Follow this and additional works at: https://digitalcommons.unl.edu/westcentresext

Part of the Agriculture Commons, Ecology and Evolutionary Biology Commons, and the Plant Sciences Commons

This Article is brought to you for free and open access by the Agricultural Research Division of IANR at DigitalCommons@University of Nebraska - Lincoln. It has been accepted for inclusion in West Central Research and Extension Center, North Platte by an authorized administrator of DigitalCommons@University of Nebraska Lincoln. 


\title{
Diurnal and Seasonal Activity Patterns of Drosophilid Species (Diptera: Drosophilidae) Present in Blackberry Agroecosystems With a Focus on Spotted-Wing Drosophila
}

\author{
Katharine A. Swoboda-Bhattarai ${ }^{1,2}$ and Hannah J. Burrack ${ }^{1}$ \\ 1 Department of Entomology and Plant Pathology, North Carolina State University, \\ Campus Box 7634, Raleigh, NC 27695 \\ 2 Current Address: Department of Entomology, University of Nebraska-Lincoln, West \\ Central Research and Extension Center, 402 W. State Farm Road, North Platte, NE \\ 69101 \\ Corresponding author — Katharine A. Swoboda-Bhattarai, email kswoboda3@unl.edu
}

\begin{abstract}
Drosophilid species with different life histories have been shown to exhibit similar behavioral patterns related to locating and utilizing resources such as hosts, mates, and food sources. Drosophila suzukii (Matsumura) is an invasive species that differs from other frugivorous drosophilids in that females lay eggs in ripe and ripening fruits instead of overripe or rotten fruits. We hypothesized that there may be diurnal and/or seasonal patterns associated with the movement of drosophilid species into and out of crop fields and their attraction to fermentation-odor-based monitoring
\end{abstract}

Published in Environmental Entomology, 2020, 11pp.

doi: $10.1093 /$ ee/nvz161

Copyright (c) 2020 Katharine A. Swoboda-Bhattarai, and Hannah J. Burrack. Published

by Oxford University Press on behalf of Entomological Society of America. Used by permission.

Submitted 25 September 2019; accepted 13 December 2019. 
traps, and that $D$. suzukii would conform to similar patterns. To test these hypotheses, we deployed passive, 2-headed Malaise traps between crop fields and wooded edges to simultaneously catch flies moving into and out of crop fields. We also deployed monitoring traps with a fermentation-based bait between crop fields and wooded edges and within crop rows. Traps were deployed weekly in June-August in 2014 and 2015 at two commercial blackberry farm in Cleveland County, NC, and were checked hourly for $24 \mathrm{~h}$, except during darkness. Both $D$. suzukii and other drosophilid species moved between crop fields and wooded edges and were attracted to monitoring traps primarily during the morning and evening hours. Whereas other drosophilids were captured in traps throughout the season, few D. suzukii were caught in traps until early to mid-July in both years and increased as the season progressed. Understanding $D$. suzukii movement and activity patterns is essential for the development of effective management strategies.

Keywords: invasive species, pest phenology, Drosophila suzukii, Rubus

Drosophila species have provided scientists with an invaluable tool with which to study evolution and behavioral innovation. Changes in behavior, along with a combination of reproductive and ecological traits including high fecundity, short generation times, and adaptation to a wide range of niches have allowed several Drosophila species to expand far beyond their ancestral ranges (Ometto et al. 2013). Drosophila melanogaster Meigen (Diptera: Drosophilidae) is a classic example, whose current worldwide distribution is the result of an out-of-Africa expansion that began 15,000 yr ago (David and Capy 1988). Similarly, Drosophila subobscura Collin (Diptera: Drosophilidae) is a Palearctic species that rapidly invaded broad latitudinal ranges in North and South America beginning in the early 1980s (Pascual et al. 2007). Recently, another drosophilid species has undergone a dramatic range expansion, but differs from previous invaders in that it is a crop pest of great concern. Drosophila suzukii (Matsumura) (Diptera: Drosophilidae) differs from other frugivorous drosophilids in that females lay eggs in ripe and ripening fruits instead of overripe or rotten fruits, and can thereby cause significant economic damage to small fruits and stone fruit crops. This difference in ecology is reflected in morphological adaptations such as the large sclerotized ovipositor that $D$. suzukii females use to lay eggs in intact, sound fruit (Atallah et al. 2014), but is it also reflected in behavioral adaptions that differentiate $D$. suzukii from other drosophilids present in the same systems? 
Drosophilid species with different life histories have been shown to exhibit similar behavioral patterns related to locating and utilizing resources such as hosts, mates, and food sources (Hoffmann and Parson 1984, Markow and O'Grady 2008). For example, adults of a wide range of Drosophila species are attracted to simple banana baits fermented with Saccharomyces cerevisiae, even though their natural feeding and breeding sites are very different (Markow and O'Grady 2008). Several Drosophila species have been shown to be attracted to such baits and other food sources during the morning and late afternoon/evening hours (Dobzhansky and Epling 1944, Pavan et al. 1950, Mitchell and Epling 1951, Miller and Weeks 1964, Noor 1998). It may be possible to illuminate some aspects of $D$. suzukii ecology by looking at the movement and behavioral patterns of other co-occurring drosophilid species.

Drosophila suzukii is endemic to Southeast Asia and is present in several countries with temperate climates from Pakistan to Japan (Kanzawa 1939, Cini et al. 2014). It was first described as a pest of cherries in Japan in the 1930s (Kanzawa 1935) and quickly became one of the most abundant drosophilid species in some Hawaiian ecosystems after its detection in the early 1980s (Kaneshiro 1983, Asquith and Messing 1992, Leblanc et al. 2009). It was first detected in the continental United States in California in 2008 and again in Florida in 2009, and has since been detected throughout much of North America (Hauser 2011) and Europe (Cini et al. 2012), and in South America (Depra et al. 2014).

With the exception of Hawaii, D. suzukii has caused economic losses throughout its introduced range. There is zero tolerance for larval infestation in harvested fruit, and in grapes, egg laying alone may result in increased disease incidence (loriatti et al. 2018). Assuming $20 \%$ yield loss, revenue losses to $D$. suzukii in strawberries, blueberries, raspberries, blackberries, and cherries in California, Oregon, and Washington alone have been estimated at $\$ 511$ million annually (Bolda et al. 2010, Walsh et al. 2011). Estimated revenue losses to the berry industry in Trento Province, Italy, decreased from 13 to $7 \%$ of the industry's output after an integrated control strategy for $D$. suzukii was implemented in the area (De Ros et al. 2015).

Recent research has illuminated aspects of $D$. suzukii resource use. Females prefer some crop hosts over others for oviposition, and 
offspring perform better on preferred female oviposition substrates such as caneberries (blackberries and raspberries), cherries, blueberries, and strawberries (Bellamy et al. 2013, Burrack et al. 2013, Diepenbrock et al. 2016). Host phenology drives infestation timing, with flies preferring soft ripe fruit over firm unripe fruit (Burrack et al. 2013, Lee et al. 2016, Swoboda-Bhattarai and Burrack 2016). The presence of non-crop habitat, which can serve as a source of infesting populations or provide $D$. suzukii with refuge from management treatments within crop fields, might also affect $D$. suzukii activity patterns related to host use (Klick et al. 2016, Tonina et al. 2018). Despite these and other recent advances, more information regarding the behavior of $D$. suzukii in agroecosystems is needed in order to develop management strategies that go beyond preventative insecticide use.

Drosophila suzukii activity has been studied in controlled environments and observed in commercial blueberry fields. Adults were most active at dawn and dusk under simulated 'summer' conditions in the laboratory (Hamby et al. 2013) and generally displayed morning and evening peaks of activity with inactive periods during the afternoon and nighttime hours under semi-natural conditions (Ferguson et al. 2015). Similarly, D. suzukii adults exhibited the greatest activity during the morning and evening hours in blueberry plantings (Evans et al. 2017, Van Timmeren et al. 2017).

We conducted experiments in 2014 and 2015 to track the temporal and spatial movement of drosophilid species in blackberry agroecosystems. Our objectives were to determine whether there are diurnal patterns associated with drosophilid 1) movement between crop fields and adjacent wooded areas, 2) attraction to monitoring traps baited with a yeast and sugar solution, and 3) seasonal changes to these patterns. For $D$. suzukii, we also sought to relate patterns of movement and trap attraction to oviposition behavior. Blackberry is a preferred D. suzukii crop host (Lee et al. 2011, Bellamy et al. 2013, Burrack et al. 2013) and insecticide-treated farms still support high fly populations. We focused on wooded areas because the presence of woodland may affect the activity patterns and relative abundance of $D$. suzukii adults in crop fields (Pelton et al. 2016), and D. suzukii populations may spill over from wooded areas into crop fields (Tonina et al. 2018). We chose to use yeast and sugar bait in monitoring traps because it is a food bait that releases fermentation- based 
volatiles that are attractive to both sexes and that is used widely for D. suzukii monitoring (Burrack et al. 2015). We expected that drosophilid species would exhibit both diurnal and seasonal patterns related to movement and trap attraction in blackberry agroecosystems and that the patterns observed for $D$. suzukii would be similar to those of other drosophilids in the system.

\section{Materials and Methods}

\section{Sampling Period}

We observed fly activity at two commercial blackberry farms in Cleveland County, North Carolina, in 2014 and 2015. Each farm was sampled every $2 \mathrm{wk}$, weather permitting, starting before ripe berries were present and continuing through the postharvest period. In both years, we sampled at each farm at least once 1) before the host crop ripened, 2) during fruit harvest, and 3) postharvest, except at Farm 2 in 2014 when no postharvest sample was collected. The number of sample dates differed between farms and years due to inclement weather and on-farm activities that precluded sampling. Sample dates were timed to crop phenology instead of week of the year, and we started collecting samples at Farm 1 earlier in 2015 than during 2014. We sampled a total of seven times in 2017 and 11 times in 2015, for a total of 18 sampling dates across the $2 \mathrm{yr}$ at the two farms (Table 1). Irrigation, fertilization, and weed management inputs at both farms followed standard agronomic practices for the region. Weekly insecticide applications for $D$. suzukii control were made at both farms during the study period. Wild brambles (Rubus spp.) and American pokeweed (Phytolacca americana), two confirmed non-crop hosts for D. suzukii, were present along the wooded edge at each farm.

Movement Between Crop Fields and Non-crop Habitat, 2014-2015

We used EZ-Migration traps (BugDorm, Taiwan), which are two-headed, unbaited Malaise traps designed to simultaneously capture insects moving in two opposite directions by funneling them into separate collection canisters, which we filled with $70 \%$ ethanol. On each sampling 
Table 1. Season, sampling date, and time of day when Malaise traps and monitoring traps with a fermentationbased bait were deployed for a 24-h period at two blackberry farms during 2014 and 2015, and the sunset and sunise times for Cleveland County, NC

\begin{tabular}{|c|c|c|c|c|c|c|c|}
\hline Year & Farm & Season & $\begin{array}{l}\text { Sampling date } \\
\text { (Start time) }\end{array}$ & $\begin{array}{l}\text { Malaise traps } \\
\text { deployed }\end{array}$ & $\begin{array}{l}\text { Monitoring } \\
\text { traps deployed }\end{array}$ & $\begin{array}{l}\text { Sunset times } \\
\text { (p.m.) }\end{array}$ & $\begin{array}{c}\text { Sunrise } \\
\text { times (a.m.) }\end{array}$ \\
\hline \multirow[t]{8}{*}{2014} & \multirow[t]{4}{*}{1} & Preharvest & 14-15 June (12:00 p.m.) & 4 & 8 & $8: 41$ & $6: 10$ \\
\hline & & Harvest & 11-12 July (5:00 p.m.) & 4 & 8 & $8: 42$ & $6: 20$ \\
\hline & & Harvest & 25-26 July (12:00 p.m.) & 4 & 8 & $8: 34$ & $6: 30$ \\
\hline & & Postharvest & 30-31 Aug. (2:00 p.m.) & 4 & 8 & 7:55 & 6:57 \\
\hline & \multirow[t]{4}{*}{2} & Preharvest & 6-7 June (7:00 p.m.) & 4 & 8 & 8:39 & 6:11 \\
\hline & & Harvest & 21-22 June (2:00 p.m.) & 4 & 8 & 8:44 & 6:11 \\
\hline & & Harvest & 5-6 July (2:00 p.m.) & 4 & 8 & 8:45 & 6:17 \\
\hline & & Postharvest & - & - & - & - & - \\
\hline \multirow[t]{11}{*}{2015} & \multirow[t]{7}{*}{1} & Preharvest & 6-7 June (2:00 p.m.) & 4 & 10 & 8:37 & 6:11 \\
\hline & & Harvest & 20-21 June (1:00 p.m.) & 4 & 10 & 8:43 & 6:11 \\
\hline & & Harvest & 6-7 July (11:00 a.m.) & 4 & 10 & 8:43 & 6:17 \\
\hline & & Harvest & 19-20 July (10:00 a.m.) & 4 & 10 & 8:38 & $6: 25$ \\
\hline & & Harvest & 3-4 Aug. (10:00 a.m.) & 4 & 10 & 8:27 & 6:36 \\
\hline & & Postharvest & 17-18 Aug. (11:00 a.m.) & 4 & 10 & 8:12 & $6: 47$ \\
\hline & & Postharvest & 29-30 Aug. (11:00 a.m.) & 4 & 10 & 7:57 & 6:56 \\
\hline & \multirow[t]{4}{*}{2} & Preharvest & 12-13 June (1:00 p.m.) & 4 & 10 & 8:42 & $6: 10$ \\
\hline & & Harvest & 28-29 June (3:00 p.m.) & 4 & 10 & 8:45 & $6: 14$ \\
\hline & & Harvest & 24-25 July (2:00 p.m.) & 4 & 10 & 8:36 & $6: 29$ \\
\hline & & Postharvest & 24-25 Aug. (11:00 a.m.) & 4 & 10 & 8:04 & $6: 53$ \\
\hline
\end{tabular}

The number of sample dates differed between farms and years due to inclement weather and on-farm activities that precluded sampling.

date, we set up four Malaise traps in the grassy area between the crop field and the wooded edge (Fig. 1). Traps were set up perpendicular to and located $\sim 3 \mathrm{~m}$ away from the end of the crop rows. During each sampling period, we checked traps hourly, on the hour, from approximately 5:00 a.m. to 10:00 p.m. (daylight hours), once after it was completely dark, and once before sunrise. The insects in each canister were removed whenever a Drosophila-like insect was captured or after every $4 \mathrm{~h}$, whichever occurred first. Insects were removed by pouring the canister contents through a handheld kitchen strainer; all insects present were collected using soft forceps and placed into a $20 \mathrm{ml}$ scintillation vial with $70 \%$ ethanol. Samples were examined under a stereomicroscope. All D. suzukii and non-D. suzukii Drosophilidae were identified, sexed, and counted, and preserved in $70 \%$ ethanol for future use. Because this experiment was conducted in commercial fields, the large 

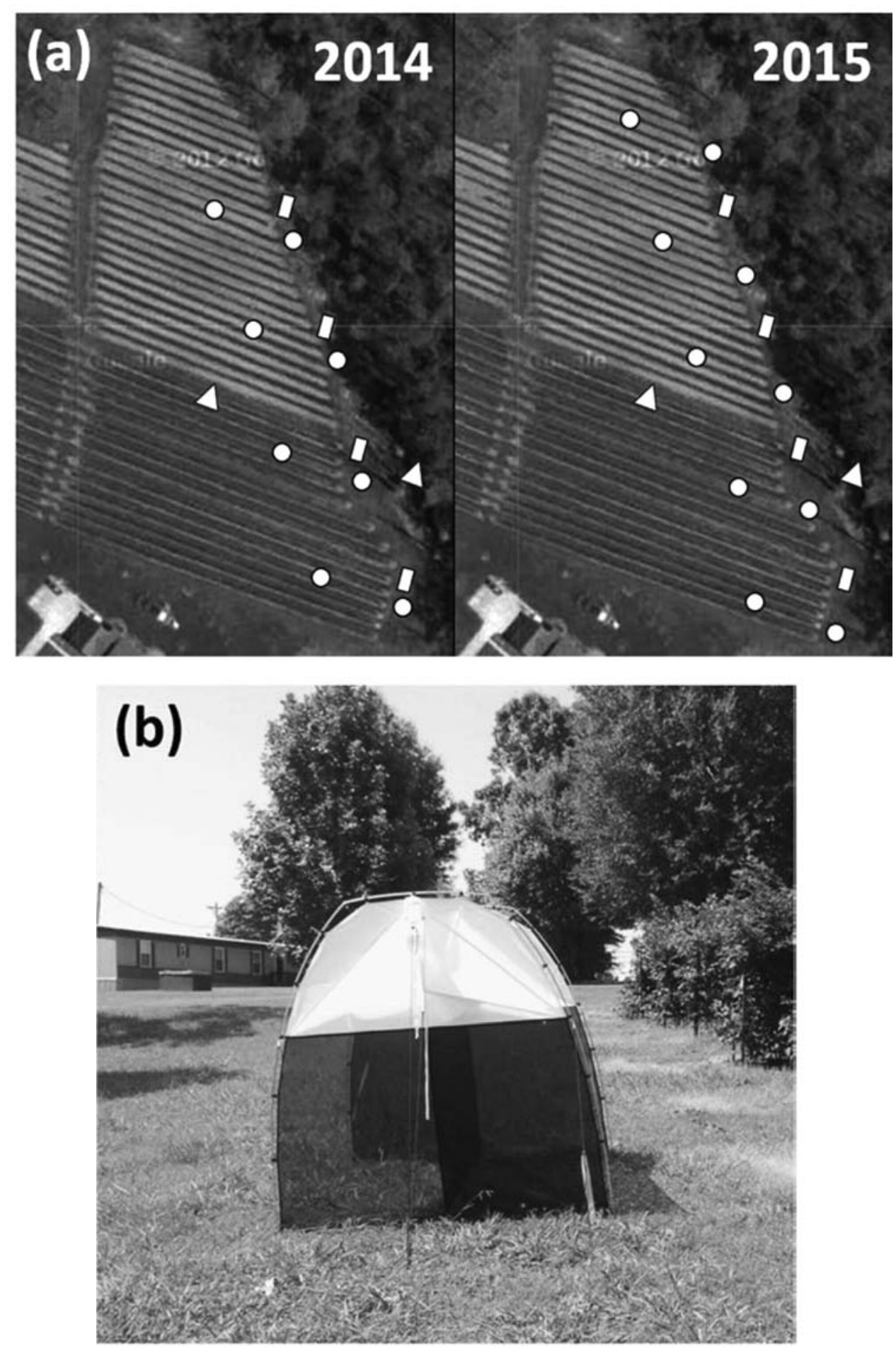

Fig. 1. (a) Placement and orientation of Malaise traps (rectangles) and monitoring traps with a fermentation-based bait (circles) used to determine the movement and activity patterns of D. suzukii at Farm 1 in North Carolina in 2014 and 2015. Data loggers (triangles) were placed within the field and along the wooded edge to record abiotic conditions. (b) Side view of a Malaise trap. 
Malaise traps could not be left out for longer than $24 \mathrm{~h}$ and were removed between sampling dates.

Attraction to Monitoring Traps With a Fermentation-Based Bait, 2014-2015

Monitoring traps consisted of $32 \mathrm{fl} \mathrm{oz}$. clear plastic cups and lids with 10 equidistant holes drilled near the top (DeliPRO brand, Tripack Industrial USA, White Plains, NY) baited with $1.69 \mathrm{~g}$ of dry active yeast, $8.45 \mathrm{~g}$ of sugar, and $150 \mathrm{ml}$ of water (Burrack et al. 2015). In concert with the Malaise trap experiment described above, we set up four traps with yeast/sugar bait between the crop field and wooded edge and four traps within the crop field. Monitoring traps placed within the crop field at Farm 1 were located $\sim 30$ m away from the wooded edge (Fig. 1). Because the wooded edge was located farther away from the crop field at Farm 2, monitoring traps were set up $17.7 \mathrm{~m}$ from the end of crop rows to keep the within-field spacing consistent between the two farms.

In 2014, we deployed monitoring traps next to the Malaise traps because another experiment was being conducted in the same field. However, because the monitoring traps proved to be very attractive to $D$. suzukii in 2014, we placed the Malaise and monitoring traps farther apart in 2015 to reduce the likelihood of interference occurring between the two types of traps. We also added an extra pair of monitoring traps in 2015 so that each Malaise trap had an equidistant monitoring trap set up on either side. In both years, monitoring traps in line with the Malaise traps were set up $\sim 3 \mathrm{~m}$ away from the end of the crop row.

Monitoring traps were also checked hourly as described above for the Malaise traps. Flies were collected from the surface of the bait using soft forceps and placed into vials with $70 \%$ ethanol; the contents of each monitoring trap were then poured through a handheld kitchen strainer to look for flies that may have drowned. During 2014 collections, we observed that many flies were present on the outside of the monitoring traps but did not necessarily enter them. Therefore, starting in late July 2014 and during the entire 2015 season, flies were aspirated off the surface of monitoring traps using a handheld aspirator (BioQuip, Rancho Dominguez, CA) for 1 min before flies were collected from within traps. Flies collected off the surface of monitoring traps 
were transferred to a separate vial with $70 \%$ ethanol. All Drosophilidae captured were separated by $D$. suzukii and non-D. suzukii, sexed, counted, and preserved for later identification to species.

Two WatchDog data loggers (Model A150, Spectrum Technologies, Inc., Aurora, IL) housed within radiation shields (WatchDog Item Number 3663A) were used to record hourly ambient temperatures during each sampling period in 2015. One logger was placed within the crop field $\sim 60 \mathrm{~m}$ away from the wooded edge, while another was placed along the wooded edge in line with the other logger (Fig. 1). Both loggers were hung $\sim 1.5 \mathrm{~m}$ off the ground, on a trellis post within the crop field and on a tree branch along the wooded edge.

Oviposition Behavior, 2015

To determine when $D$. suzukii females lay eggs in fruit throughout the day, infestation rates were compared in blackberries that were exposed to wild flies from 6:00 to 10:00 a.m., 10:00 a.m. to 2:00 p.m., 2:00 to 6:00 p.m., 6:00 to 10:00 p.m., or overnight from 10:00 p.m. to 6:00 a.m. On 20 July at Farm 1, small 5-7" handmade mesh bags with drawstring closures were placed over clusters of unripe blackberries to prevent oviposition. Six clusters were bagged in each of the 10 rows (60 clusters total) between the two northernmost Malaise traps. Clusters were bagged in the first trellis section of each row, closest to the wooded edge, and were left to ripen in the bags. During the next sampling period (3-4 August), one bag was removed in each row during each time period totaling 10 replicates per time period. At the end of each time period, all of the ripe berries on each cluster were collected, brought back to the lab and weighed, and were individually suspended in an organza sling inside a 2 oz. plastic portion cup with holes poked in the bottom to promote juice drainage. Berries were held in a growth chamber at $20^{\circ} \mathrm{C}$ for $10 \mathrm{~d}$, at which time they were dissected, and all pupae moved to a small Petri dish with a moistened paper towel square until adults emerged and were confirmed to be $D$. suzukii.

\section{Data Analyses}

Unless otherwise noted, data were analyzed using generalized linear mixed models with a lognormal distribution and an identity link 
in PROC GLIMMIX in SAS v. 9.4. Post hoc means comparisons were conducted using the Tukey-Kramer adjustment in all of the following analyses. We considered each Malaise trap and set of monitoring traps (i.e., paired traps located within the crop field and between the crop field and wooded edge) as replicates in our analyses. Recent work by Kirkpatrick et al. (2018) suggested that range of attraction of a commercial attractant (Scentry) and red sticky trap combination was about $100 \mathrm{~m}$ in tart cherry orchards, postharvest (i.e., when no fruits were present), but these observations have not been replicated in other crops or during harvest. Similar range of attraction research has not been conducted for yeast and sugar baited monitoring traps, such as those we used.

Movement Between Crop Fields and Non-crop Habitat

Drosophila suzukii captures in Malaise traps were too low to analyze statistically. However, sufficient numbers of other drosophilid species were captured to allow for statistical analysis. In separate three-way analyses, we compared the numbers of females and males of non- $D$. suzukii drosophilids caught moving into or out of the crop field during five diurnal time periods and during preharvest, harvest, and postharvest periods. Direction of movement (into the field and out of the field), time period (6:00 to 10:00 a.m., 10:00 a.m. to 2:00 p.m., 2:00 to 6:00 p.m., 6:00 to 10:00 p.m., and 10:00 p.m. to 6:00 a.m.), and season (preharvest, harvest, and postharvest) were included in the model as fixed effects, while year, site, and trap were included as random effects.

Attraction to Monitoring Traps With a Fermentation- Based Bait

Because large numbers of flies were observed on the outside of traps, we first compared the number of flies aspirated off the surface of traps to the number of flies collected within traps. We calculated the total numbers of $D$. suzukii and of other drosophilid species captured at individual monitoring traps using each collection method during each 24-h sampling period when both collection methods were used (final two sampling dates in 2014 and throughout the 2015 season). We analyzed data for $D$. suzukii (females and males) and other drosophilid species (females and males) in separate two-way analyses with collection method (aspirated off the surface of traps vs. collected within 
traps) and trap placement (within the crop field vs. between the crop field and wooded edge) as fixed effects, and year, season, site, transect, and trap as random effects.

For the remaining analyses, the number of flies aspirated off the surface of a trap was combined with the number of flies captured within the trap to calculate a trap total. For the monitoring traps, we conducted a two-part analysis to determine whether there are diurnal and seasonal patterns associated with trap captures of $D$. suzukii and other drosophilid species in monitoring traps with a fermentationbased bait. First, we wanted to determine whether there are daily activity patterns associated with trap attraction and whether these patterns are affected by where traps were placed within the system (in the crop field vs. between the crop field and wooded edge). We calculated the total numbers of $D$. suzukii (females and males) and other drosophilid species (females and males) captured at individual traps during each daily time period and conducted separate two-way analyses with time period (6:00 to 10:00 a.m., 10:00 a.m. to 2:00 p.m., 2:00 to 6:00 p.m., 6:00 to 10:00 p.m., and 10:00 p.m. to 6:00 a.m.) and trap placement (within the crop field or between the crop field and the wooded edge) as fixed effects, and season, year, site, transect, and trap as random effects.

Next, we wanted to determine whether daily patterns of trap attraction changed over the course of the season and compared the numbers of $D$. suzukii (females and males) and other drosophilid species (females and males) captured during five daily time periods and during preharvest, harvest, and postharvest periods. To do so, we conducted separate two-way analyses with time period (6:00 to 10:00 a.m., 10:00 a.m. to 2:00 p.m., 2:00 to 6:00 p.m., 6:00 to 10:00 p.m., and 10:00 p.m. to 6:00 a.m.) and season (preharvest, harvest, and postharvest) as fixed effects, and trap placement, year, site, transect, and trap as random effects.

\section{Oviposition Behavior}

To determine if there are diurnal patterns associated with the oviposition behavior of $D$. suzukii females, we conducted a two-part analysis. First, to determine whether the likelihood of a berry becoming infested differs throughout the day, we compared the ratio of infested berries (number of events) over the number of exposed berries 
(number of trials) for clusters exposed during the five time periods. Data were analyzed using a generalized linear mixed model with a binomial distribution and a logit link in PROC GLIMMIX in SAS v. 9.4, with time period (6:00 to 10:00 a.m., 10:00 a.m. to 2:00 p.m., 2:00 to 6:00 p.m., 6:00 to 10:00 p.m., and 10:00 p.m. to 6:00 a.m.) and row (1-10) included in the model as fixed effects. Next, we determined if infestation rate varied among berries exposed during the five time periods using a generalized linear mixed model with a lognormal distribution and an identity link in PROC GLIMMIX in SAS v. 9.4. Time period was included in the model as a fixed effect, while row and cluster were included as random effects.

\section{Results}

At least 15 naturally occurring drosophilid species in nine genera were collected over the course of the study (Markow and O'Grady 2006, Miller et al. 2017) (Supp Table S1). Ambient temperatures were a few degrees higher on average in crop fields than along wooded edges during daylight hours and vice versa during the nighttime in 2015 (Supp Fig. 1).

\section{Supplemental Table S1}

\begin{tabular}{|c|c|c|c|}
\hline Subfamily & Subgenus & Species group & Genus or species \\
\hline \multirow[t]{2}{*}{ Steganinae } & & & Amiota sp. \\
\hline & & & Leucophenga varia (Walker) \\
\hline \multirow[t]{15}{*}{ Drosophilinae } & & & Chymomyza amoena (Loew) \\
\hline & & & Cladochaeta floridana (Malloch) \\
\hline & & & Cladochaeta inversa (Walker) \\
\hline & Drosophila & funebris & Drosophila macrospina Stalker and Spenser \\
\hline & Drosophila & testacea & Drosophila putrida Sturtevant \\
\hline & Drosophila & tripunctata & Drosophila tripunctata Loew \\
\hline & Sophophora & obscura & Drosophila affinis Sturtevant \\
\hline & Sophophora & melanogaster & Drosophila suzukii (Matsumura) \\
\hline & & & Microdrosophila quadrata (Sturtevant) \\
\hline & & & Mycodrosophila claytonae Wheeler and Takada \\
\hline & & & Mycodrosophila stalkeri Wheeler and Takada \\
\hline & & & Scaptomyza adusta (Loew) \\
\hline & & & Scaptomyza graminum (Fallén) \\
\hline & & & Scaptomyza pallida (Zetterstedt) \\
\hline & & & Zapriomus indiamus Gupta \\
\hline
\end{tabular}




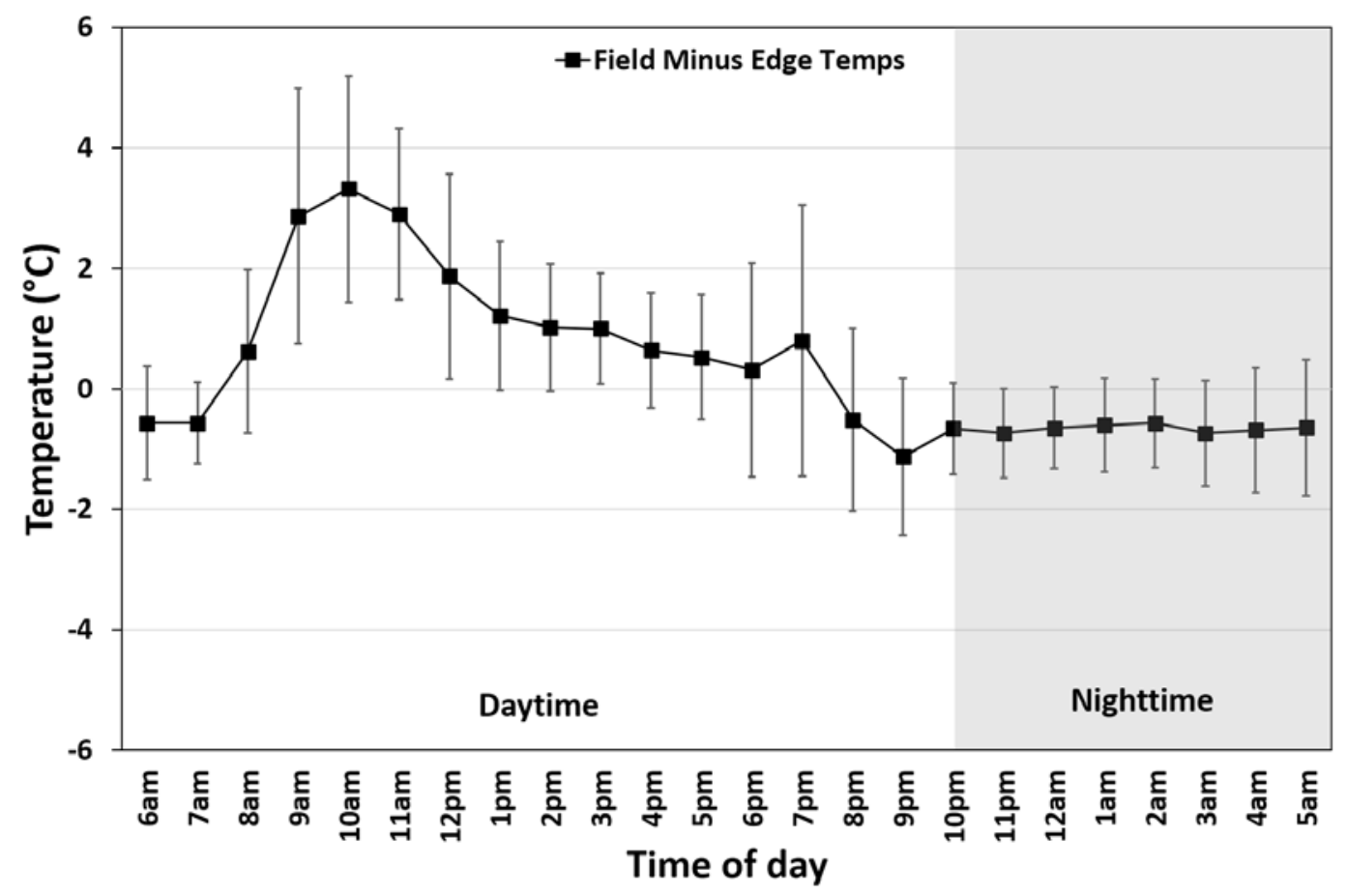

Supplemental Figure 1

Movement Between Crop Fields and Non-crop Habitat, 2014-2015

Diurnal Patterns—Malaise Traps

A total of 595 non-D. suzukii drosophilids were captured in the Malaise traps over the course of the study, although fewer flies were caught in $2014(n=141)$ than $2015(n=454)$. The overall movement of other drosophilid species into and out of the crop field followed a U-shaped pattern with peaks of movement in both directions during the morning (6:00 to $10: 00$ a.m.) and evening (6:00 to 10:00 p.m.) hours (Fig. 2a). Females and males of other drosophilid species were captured throughout the day and patterns of movement into and out of crop fields differed among time periods for both females and males. More flies were caught moving into the crop field than out of the crop field during the evening hours, whereas similar numbers of flies were caught moving into and out of the crop field during the other four time periods (time period ${ }^{\star}$ direction of movement: female: $F_{4,667}=11.79, P<0.0001$; male: $F_{4,667}=12.00, P<0.0001$ ) (Table 2). 
Malaise traps

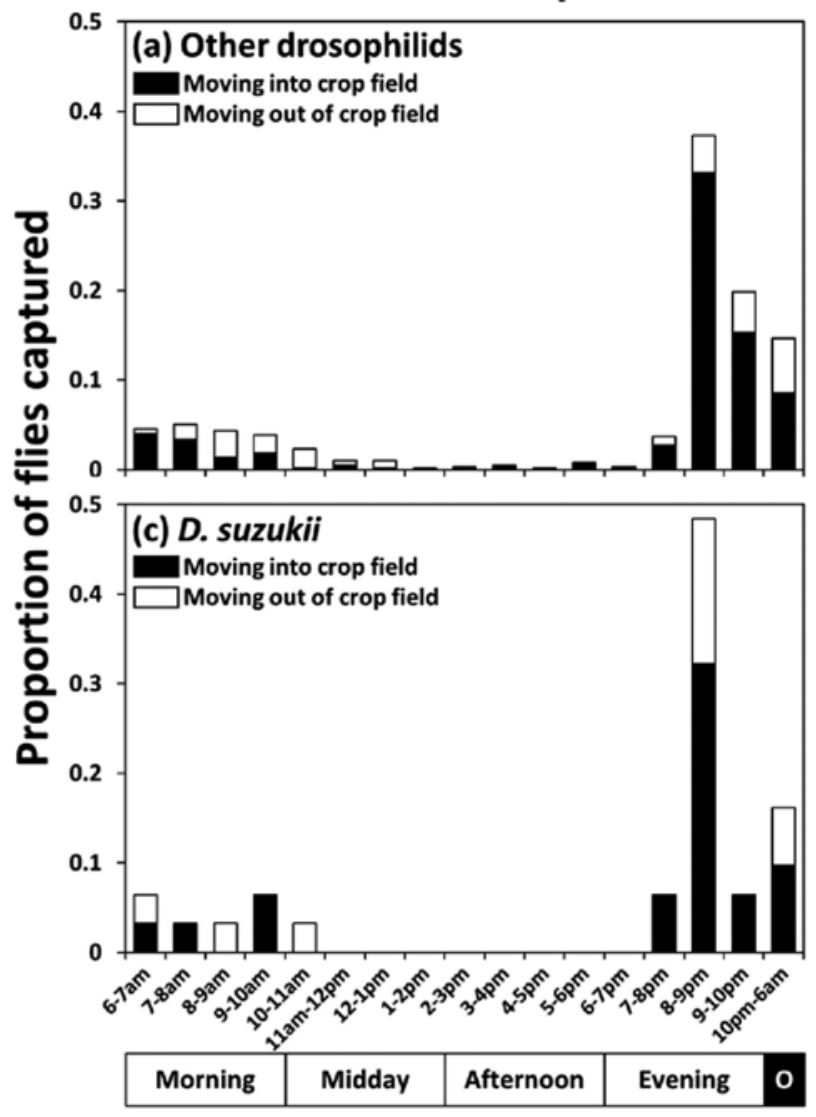

Monitoring traps

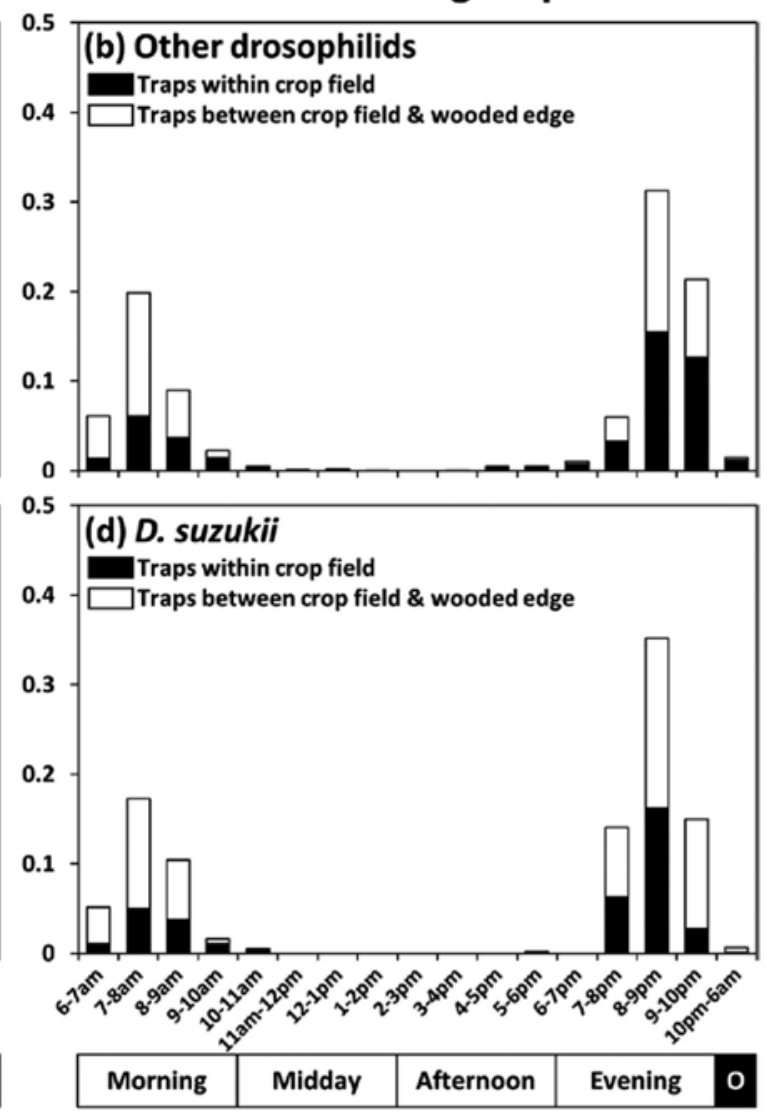

Fig. 2. Other drosophilid species $(a, b)$ and D. suzukii $(c, d)$ caught in Malaise traps while moving into or out of crop fields and in monitoring traps placed within crop fields or between crop fields and an adjacent wooded edge at each hour of the day, expressed as proportions of the total number of individuals intercepted at the two farms during the $2 \mathrm{yr}$ of study. Hours of the day are grouped into five daily time periods including morning (6:00-10:00 a.m.), midday (10:00 a.m.-2:00 p.m.), afternoon (2:00-6:00 p.m.), evening (6:00-10:00 p.m.), and overnight (10:00 p.m.-6:00 a.m.; represented by dark square with ' $O$ '). Sample sizes: Malaise traps $=595$ other drosophilids and 31 D. suzukii; monitoring traps $=2552$ other drosophilids and 933 D. suzukii.

A total of 31 D. suzukii were captured in the Malaise traps over the course of the study, with fewer D. suzukii caught in $2014(n=3)$ than in 2015 ( $n=28$ ). As was true for other drosophilid species, overall $D$. suzukii movement into and out of the crop field followed a U-shaped pattern with peaks of movement in both directions during the morning and evening hours (Fig. 2c). However, whereas other drosophilid species were captured in Malaise traps throughout the day, D. suzukii 
Table 2. The mean ( $\pm \mathrm{SE}$ ) numbers of female and male non-D. suzukii drosophilids and total numbers of female and male D. suzukii captured moving into or out of the crop field during five diurnal time periods at two commercial blackberry farms in Cleveland County, NC, in 2014 and 2015

Direction of movement

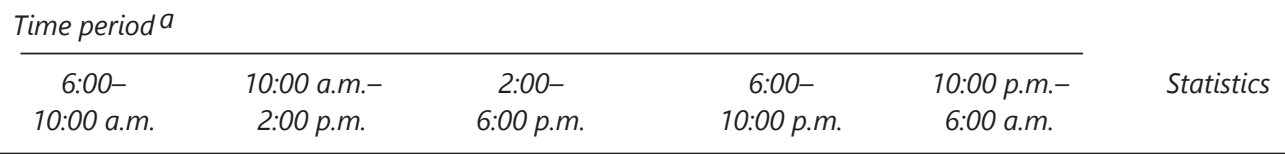

Other drosophilids

\begin{tabular}{|c|c|c|c|c|c|c|c|}
\hline \multirow[t]{2}{*}{ Females } & Into field & $0.5 \pm 0.10 b$ & $0.1 \pm 0.03 \mathrm{~cd}$ & $0.1 \pm 0.03 c d$ & $2.6 \pm 0.59 a$ & $0.5 \pm 0.13 \mathrm{bcd}$ & $F_{4,667}=11.79$ \\
\hline & Out of field & $0.4 \pm 0.11 \mathrm{bcd}$ & $0.2 \pm 0.06 \mathrm{bcd}$ & $0.0 \pm 0.00 \mathrm{~d}$ & $0.5 \pm 0.12 b c$ & $0.3 \pm 0.09 \mathrm{bcd}$ & $P<0.0001$ \\
\hline \multirow[t]{2}{*}{ Males } & Into field & $0.4 \pm 0.08 b$ & $0.0 \pm 0.02 b$ & $0.1 \pm 0.03 b$ & $1.7 \pm 0.37 a$ & $0.3 \pm 0.07 b$ & $F_{4,667}=12.00$ \\
\hline & Out of field & $0.2 \pm 0.06 b$ & $0.1 \pm 0.04 b$ & $0.0 \pm 0.01 b$ & $0.3 \pm 0.08 b$ & $0.2 \pm 0.07 b$ & $P<0.0001$ \\
\hline \multicolumn{8}{|l|}{ D. suzukii } \\
\hline \multirow[t]{2}{*}{ Females } & Into field & 4 & 0 & 0 & 10 & 3 & - \\
\hline & Out of field & 2 & 0 & 0 & 5 & 0 & - \\
\hline \multirow[t]{2}{*}{ Males } & Into field & 0 & 0 & 0 & 4 & 0 & - \\
\hline & Out of field & 0 & 1 & 0 & 0 & 2 & - \\
\hline
\end{tabular}

a. D. suzukii data were not analyzed statistically. For other drosophilids, means for females or males that share a letter are significantly different at $\alpha=5 \%$.

flies were rarely captured during the midday (10:00 a.m. to 2:00 p.m.) and afternoon (2:00 to 6:00 p.m.) hours. Twice as many D. suzukii females were caught moving into the crop field than out of the crop field during the morning and evening hours, while more $D$. suzukii males were caught moving into the crop field during the evening hours than at any other time of day (Table 2).

\section{Seasonal Patterns-Malaise Traps}

Other drosophilids were captured in the Malaise traps on all sampling dates at both sites in both years. Patterns associated with the direction of movement changed over the course of the season for non- $D$. suzukii females but not males (season ${ }^{\star}$ direction: females: $F_{2,667}=3.45$, $P=0.0324$; males: $F_{2,667}=0.70, P=0.50$ ). More females were caught moving into the crop field than out of the crop field during the preharvest period, whereas similar numbers of females were collected moving in both directions during the harvest and postharvest periods (Table 3). Overall, more males were caught moving into the crop field $(0.5 \pm 0.08)$ than out of the crop field $(0.1 \pm 0.03)$ (direction: $F_{1,667}$ $=22.80, P<0.0001)$. 
Table 3. Dates of first capture and mean $( \pm$ SE) numbers of female and male non- $D$. suzukii drosophilids and total numbers of female and male $D$. suzukii captured moving into or out of the crop field during the preharvest, harvest, and postharvest periods at two commercial blackberry farms in Cleveland County, NC, in 2014 and 2015

\begin{tabular}{|c|c|c|c|c|c|c|c|}
\hline \multirow{2}{*}{\multicolumn{2}{|c|}{ Direction of movement }} & \multicolumn{2}{|c|}{ First capture of the year } & \multicolumn{3}{|l|}{ Seasona } & \multirow[b]{2}{*}{ Statistics } \\
\hline & & 2014 & 2015 & Preharvest & Harvest & Postharvest & \\
\hline \multicolumn{8}{|c|}{ Other drosophilids } \\
\hline \multirow[t]{2}{*}{ Females } & Into field & 6 June & 6 June & $0.7 \pm 0.16 a$ & $0.8 \pm 0.22 \mathrm{ab}$ & $0.5 \pm 0.11 \mathrm{ab}$ & $F_{2,667}=3.45$ \\
\hline & Out of field & 6 June & 7 June & $0.1 \pm 0.05 c$ & $0.3 \pm 0.06 \mathrm{bc}$ & $0.4 \pm 0.10 \mathrm{abc}$ & $P=0.0324$ \\
\hline \multirow[t]{2}{*}{ Males } & Into field & 6 June & 6 June & $0.5 \pm 0.12 a$ & $0.6 \pm 0.14 a$ & $0.3 \pm 0.08 a$ & $F_{2,667}=0.70$ \\
\hline & Out of field & 6 June & 7 June & $0.1 \pm 0.03 a$ & $0.2 \pm 0.04 a$ & $0.2 \pm 0.05 a$ & $P=0.50$ \\
\hline \multicolumn{8}{|l|}{ D. suzukii } \\
\hline \multirow[t]{2}{*}{ Females } & Into field & 12 July & 3 Aug. & 0 & 15 & 2 & - \\
\hline & Out of field & 25 July & 19 July & 0 & 6 & 1 & - \\
\hline \multirow[t]{2}{*}{ Males } & Into field & - & 19 July & 0 & 4 & 0 & - \\
\hline & Out of field & 26 July & 20 July & 0 & 3 & 0 & - \\
\hline
\end{tabular}

a. D. suzukii data were not analyzed statistically. For other drosophilids, means for females or males that share a letter are significantly different at $\alpha=5 \%$.

Drosophila suzukii flies were not captured in the Malaise traps until mid-July in 2014 and in 2015. Overall, over three-fourths (87.5\%) of D. suzukii females and $100 \%$ of D. suzukii males were captured during the harvest period, while $70.8 \%$ of females and $57.1 \%$ of males were captured while moving into the crop field (Table 3).

\section{Attraction to Monitoring Traps With a Fermentation-Based Bait, 2014-2015}

\section{Collection Method-Monitoring Traps}

A total of 2,552 non-D. suzukii drosophilids ( 1,533 females and 1,019 males) were caught at monitoring traps over the course of the study, with fewer flies caught in $2014(n=232)$ than $2015(n=2,320)$. Males of other drosophilid species were observed to court other flies on the surface of monitoring traps. Despite this observation, males of other drosophilid species were caught inside of monitoring traps (4.6 \pm 0.62$)$ more often than they were aspirated off the surface of traps (3.0 \pm 0.39) $\left(F_{1,220}=6.85, P=0.0095\right)$. Females of other drosophilid species 
were also caught within traps $(7.6 \pm 0.97)$ more often than they were caught on the surface of traps $(3.9 \pm 0.48)\left(F_{1,220}=19.15, P<0.0001\right)$. These results were similar for traps placed within the crop field and for traps placed between the crop field and wooded edge (collection method*trap placement: female: $F_{1,220}=0.09, P=0.76$; male: $F_{1,220}=$ $0.16, P=0.69)$.

A total of 933 D. suzukii (717 females and 216 males) were caught at monitoring traps over the course of the study, with fewer flies collected in 2014 ( $n=144)$ than in 2015 ( $n=789)$. We observed $D$. suzukii male courting behavior, male-male aggression, and mating pairs on the surface of some monitoring traps and on nearby fruits and leaves. Despite this observation, $D$. suzukii males were caught within traps $(0.8 \pm 0.16)$ as often as they were aspirated off the surface of traps $(0.9 \pm 0.18)\left(F_{1,220}=0.55, P=0.50\right)$. Female $D$. suzukii were also caught within traps $(4.0 \pm 0.85)$ as often as they were caught on the surface of traps $(1.7 \pm 0.28)\left(F_{1,220}=3.53, P=0.06\right)$. These patterns were not affected by trap placement; results were similar for traps placed within the crop field and for traps placed between the crop field and wooded edge (collection method*trap placement: females: $F_{1,220}=0.05, P=0.82$; males: $\left.F_{1,220}=0.57, P=0.45\right)$.

Diurnal Patterns-Monitoring Traps

As was true for the Malaise traps, the diurnal patterns of attraction to monitoring traps exhibited by non-D. suzukii drosophilids followed a U-shaped pattern (Fig. 2b). The number of other drosophilids caught at monitoring traps during the five time periods was affected by where traps were placed within the system (time period*trap placement: females: $F_{4,724}=6.18, P<0.0001$; males: $F_{4,724}$ $=2.86, P=0.0227$ ) (Table 4). More flies were caught at monitoring traps placed between the crop field and wooded edge than at traps placed within the crop field during the morning hours, whereas flies were captured equally often at traps placed in the two locations during the other four time periods. As was true for other drosophilids, the capture of $D$. suzukii flies at monitoring traps also followed a $U$ shaped pattern (Fig. 2d). However, unlike other drosophilids, the numbers of $D$. suzukii caught at monitoring traps during the five time periods was not affected by where traps were placed within the system (Table 4). Instead, significantly more $D$. suzukii females were 
Table 4. Mean $( \pm \mathrm{SE})$ numbers of non-D. suzukii drosophilids (females and males) and D. suzukii (females and males) captured at monitoring traps with a fermentation-based bait during five diurnal time periods, and at traps placed within the crop field or at traps placed between the crop field and wooded edge, at two commercial blackberry farms in Cleveland County, NC, in 2014 and 2015.

\begin{tabular}{|c|c|c|c|c|c|}
\hline \multirow[t]{2}{*}{ Variablea } & \multirow[t]{2}{*}{ Trap placement } & \multicolumn{2}{|c|}{ Other drosophilids } & \multicolumn{2}{|l|}{ D. suzukii } \\
\hline & & Females & Males & Females & Males \\
\hline \multicolumn{6}{|c|}{ Time period*trap placement } \\
\hline \multirow[t]{2}{*}{ 6:00-10:00 a.m. } & Within field & $2.3 \pm 0.43 b$ & $1.8 \pm 0.36 b$ & $0.9 \pm 0.29 a$ & $0.3 \pm 0.09 a$ \\
\hline & Between field and edge & $4.7 \pm 0.66 a$ & $2.8 \pm 0.44 a$ & $1.9 \pm 0.53 a$ & $0.7 \pm 0.19 a$ \\
\hline \multirow[t]{2}{*}{ 10:00 a.m.-2:00 p.m. } & Within field & $0.2 \pm 0.06 c$ & $0.0 \pm 0.02 c$ & $0.0 \pm 0.03 a$ & $0.0 \pm 0.00 a$ \\
\hline & Between field and edge & $0.4 \pm 0.02 c$ & $0.0 \pm 0.02 c$ & $0.0 \pm 0.01 a$ & $0.0 \pm 0.00 a$ \\
\hline \multirow[t]{2}{*}{ 2:00-6:00 p.m. } & Within field & $0.2 \pm 0.08 c$ & $0.0 \pm 0.02 c$ & $0.0 \pm 0.01 a$ & $0.0 \pm 0.00 a$ \\
\hline & Between field and edge & $0.1 \pm 0.03 c$ & $0.0 \pm 0.00 c$ & $0.0 \pm 0.01 a$ & $0.0 \pm 0.00 a$ \\
\hline \multirow[t]{2}{*}{ 6:00-10:00 p.m. } & Within field & $6.1 \pm 1.33 a$ & $4.4 \pm 1.07 a$ & $2.5 \pm 0.72 a$ & $0.5 \pm 0.17 a$ \\
\hline & Between field and edge & $5.1 \pm 0.86 a$ & $3.3 \pm 0.46 a$ & $3.4 \pm 0.85 a$ & $1.0 \pm 0.24 a$ \\
\hline \multirow[t]{4}{*}{ 10:00 p.m.-6:00 a.m. } & Within field & $0.2 \pm 0.07 c$ & $0.3 \pm 0.10 b c$ & $0.0 \pm 0.02 a$ & $0.0 \pm 0.00 a$ \\
\hline & Between field and edge & $0.1 \pm 0.03 c$ & $0.0 \pm 0.03 c$ & $0.0 \pm 0.04 a$ & $0.0 \pm 0.02 a$ \\
\hline & & $F_{4,724}=6.18$ & $F_{4,724}=2.86$ & $F_{4,724}=1.61$ & $F_{4,724}=1.94$ \\
\hline & & $P<0.0001$ & $P<0.0001$ & $P=0.1692$ & $P=0.1021$ \\
\hline \multicolumn{6}{|l|}{ Time period } \\
\hline 6:00-10:00 a.m. & Both placements & - & - & $1.4 \pm 0.31 b$ & $0.5 \pm 0.11 a$ \\
\hline 10:00 a.m.-2:00 p.m. & Both placements & - & - & $0.0 \pm 0.02 c$ & $0.0 \pm 0.00 b$ \\
\hline 2:00-6:00 p.m. & Both placements & - & - & $0.0 \pm 0.01 c$ & $0.0 \pm 0.00 b$ \\
\hline 6:00-10:00 p.m. & Both placements & - & - & $2.9 \pm 0.56 a$ & $0.8 \pm 0.15 a$ \\
\hline \multirow[t]{3}{*}{ 10:00 p.m.-6:00 a.m. } & Both placements & - & - & $0.0 \pm 0.02 c$ & $0.0 \pm 0.01 b$ \\
\hline & & & & $F_{4,724}=40.03$ & $F_{4,724}=26.15$ \\
\hline & & & & $P<0.0001$ & $P<0.0001$ \\
\hline \multicolumn{6}{|l|}{ Trap placement } \\
\hline All periods & Within field & - & - & $0.7 \pm 0.17 b$ & $0.2 \pm 0.04 b$ \\
\hline \multirow[t]{3}{*}{ All periods } & Between field and edge & - & - & $1.1 \pm 0.22 a$ & $0.4 \pm 0.07 a$ \\
\hline & & & & $F_{1,724}=5.01$ & $F_{1,724}=6.44$ \\
\hline & & & & $P=0.0255$ & $P=0.0114$ \\
\hline
\end{tabular}

$a$. For females and males of other drosophilid species and $D$. suzukii, means that share a letter within a column for each separate analysis (time period*trap placement, time period, and trap placement) are not significantly different at $\alpha=5 \%$.

caught during the evening than during the morning hours, while more $D$. suzukii females and males were caught during the evening and morning hours than during the midday, afternoon, and overnight hours (time period: females: $F_{4,724}=40.03, P<0.0001$; males: $\left.F_{4,724}=26.15, P<0.0001\right)$. Overall, more $D$. suzukii females and males were caught at traps placed between the crop field than in traps placed within the crop field (trap placement: females: $F_{1,724}=5.01, P$ $=0.0255$; males: $F_{1,724}=6.44, P=0.0114$ ). 
Table 5. Total and mean $( \pm \mathrm{SE}$ ) numbers of non-D. suzukii drosophilids (females and males) and D. suzukii (females and males) captured during five diurnal time periods during the preharvest, harvest, and postharvest periods at two commercial blackberry farms in Cleveland County, NC, in 2014 and 2015.

\begin{tabular}{|c|c|c|c|c|c|c|}
\hline \multirow[t]{2}{*}{ Time period $a$} & \multicolumn{3}{|c|}{ Other drosophilids } & \multicolumn{3}{|l|}{ D. suzukii } \\
\hline & Preharvest & Harvest & Postharvest & Preharvest & Harvest & Postharvest \\
\hline \multicolumn{7}{|l|}{ Females } \\
\hline No. captured & 54 & 739 & 740 & 13 & 238 & 466 \\
\hline 6:00-10:00 a.m. & $1.3 \pm 0.48 a$ & $2.5 \pm 0.45 a$ & $8.0 \pm 1.01 a$ & $0.3 \pm 0.13 a$ & $0.6 \pm 0.18 a b$ & $4.3 \pm 1.12 b$ \\
\hline 10:00 a.m.-2:00 p.m. & $0.0 \pm 0.00 a$ & $0.0 \pm 0.02 b$ & $0.3 \pm 0.12 b$ & $0.1 \pm 0.06 a$ & $0.0 \pm 0.02 \mathrm{~b}$ & $0.0 \pm 0.02 c$ \\
\hline 2:00-6:00 p.m. & $0.0 \pm 0.03 a$ & $0.2 \pm 0.07 \mathrm{~b}$ & $0.2 \pm 0.07 b$ & $0.0 \pm 0.00 a$ & $0.0 \pm 0.02 \mathrm{~b}$ & $0.0 \pm 0.00 c$ \\
\hline 6:00-10:00 p.m. & $0.3 \pm 0.15 a$ & $5.2 \pm 1.12 \mathrm{a}$ & $11.1 \pm 1.6 \mathrm{a}$ & $0.0 \pm 0.00 a$ & $1.9 \pm 0.57 a$ & $7.9 \pm 1.71 a$ \\
\hline \multirow[t]{2}{*}{ 10:00 p.m.-6:00 a.m. } & $0.0 \pm 0.00 a$ & $0.2 \pm 0.05 b$ & $0.0 \pm 0.00 \mathrm{~b}$ & $0.0 \pm 0.00 a$ & $0.0 \pm 0.03 b$ & $0.0 \pm 0.00 c$ \\
\hline & \multicolumn{3}{|c|}{$F_{8,720}=19.02, P<0.0001$} & \multicolumn{3}{|c|}{$F_{8,720}=19.63, P<0.0001$} \\
\hline \multicolumn{7}{|l|}{ Males } \\
\hline No. captured & 36 & 466 & 517 & 14 & 99 & 103 \\
\hline 6:00-10:00 a.m. & $0.6 \pm 0.23 a$ & $1.6 \pm 0.31 a$ & $5.4 \pm 0.72 a$ & $0.4 \pm 0.16 a$ & $0.5 \pm 0.16 a$ & $0.8 \pm 0.19 b$ \\
\hline 10:00 a.m.-2:00 p.m. & $0.0 \pm 0.00 a$ & $0.0 \pm 0.00 \mathrm{~b}$ & $0.1 \pm 0.06 b$ & $0.0 \pm 0.00 a$ & $0.0 \pm 0.00 \mathrm{~b}$ & $0.0 \pm 0.00 c$ \\
\hline 2:00-6:00 p.m. & $0.0 \pm 0.00 a$ & $0.0 \pm 0.01 b$ & $0.0 \pm 0.03 b$ & $0.0 \pm 0.00 a$ & $0.0 \pm 0.00 \mathrm{~b}$ & $0.0 \pm 0.00 c$ \\
\hline 6:00-10:00 p.m. & $0.5 \pm 0.15 a$ & $3.2 \pm 0.72 a$ & $8.0 \pm 1.48 a$ & $0.0 \pm 0.00 a$ & $0.6 \pm 0.18 a$ & $1.9 \pm 0.41 a$ \\
\hline \multirow[t]{2}{*}{ 10:00 p.m.-6:00 a.m. } & $0.1 \pm 0.05 a$ & $0.2 \pm 0.07 b$ & $0.0 \pm 0.00 \mathrm{~b}$ & $0.0 \pm 0.04 a$ & $0.0 \pm 0.01 b$ & $0.0 \pm 0.00 c$ \\
\hline & \multicolumn{3}{|c|}{$F_{8,720}=18.00, P<0.0001$} & \multicolumn{3}{|c|}{$F_{8,720}=8.82, P<0.0001$} \\
\hline
\end{tabular}

a. Means that share a letter for other drosophilid females, other drosophilid males, D. suzukii females, or D. suzukii males are not significantly different at $\alpha=5 \%$.

\section{Seasonal Patterns-Monitoring Traps}

Females and males of other drosophilid species were caught at monitoring traps on all sampling dates at both sites in both years. The number of non-D. suzukii drosophilids caught at monitoring traps increased over the course of the season, while the diurnal patterns of their attraction to monitoring traps also changed (Table 5). Preharvest, the numbers of females and males of other drosophilid species caught at monitoring traps did not differ among the five daily time periods. In contrast, during the harvest and postharvest periods, more females and males were caught during the evening and morning hours than during the other time periods (time period ${ }^{*}$ season: females: $F_{8,720}=$ 19.02, $P<0.0001$; males: $F_{8,720}=18.00, P<0.0001$ ).

Females and males of $D$. suzukii were not caught at monitoring traps until 11 July and 25 July in 2014, respectively. Although several D. suzukii females and males were caught in early June in 2015 , very 
few additional flies were caught until mid- to late July in 2015. The number of $D$. suzukii caught at monitoring traps increased over the course of the season, while the diurnal patterns of $D$. suzukii attraction to monitoring traps also changed (Table 5). The few D. suzukii females and males that were caught during the preharvest period were caught in monitoring traps equally often during the five daily time periods. In contrast, during the harvest period, more $D$. suzukii females were caught during the evening hours than during the midday, afternoon, and overnight hours, whereas more $D$. suzukii males were caught during the evening and morning hours than during the other time periods. Postharvest, more $D$. suzukii females and males were caught during the evening hours than during the other time periods, and during the morning hours than during the midday, afternoon, and overnight hours (time period*season: females: $F_{8,720}=19.63, P<0.0001$; males: $\left.F_{8,720}=8.82, P<0.0001\right)$.

\section{D. suzukii Oviposition Behavior, 2015}

No D. suzukii were reared from berries exposed from 10:00 a.m. to 2:00 p.m. and overnight from 10:00 p.m. to 6:00 a.m. (Table 6); these two periods correspond with times of the day when little to no $D$. suzukii activity was observed at the Malaise and monitoring traps. Conversely, at least one $D$. suzukii was reared from berries exposed during the three remaining time periods. Infestation rates were higher in berries exposed during the evening hours, although the likelihood

Table 6. Proportions of infested berries and mean infestation rates in blackberries exposed during five time periods on 3-4 August 2015 at a commercial blackberry farm in Cleveland, County, NC.

\begin{tabular}{lll} 
Time period $a$ & $\begin{array}{l}\text { Proportion of berries } \\
\text { infested (no. exposed) }\end{array}$ & $\begin{array}{l}\text { Mean D. suzukii } \\
\text { per berry }\end{array}$ \\
\hline 6:00-10:00 a.m. & $0.18(22)$ & $0.3 \pm 0.12 \mathrm{ab}$ \\
10:00 a.m.-2:00 p.m. & $0.00(20)$ & $0.0 \pm 0.00 \mathrm{~b}$ \\
2:00-6:00 p.m. & $0.05(22)$ & $0.0 \pm 0.05 \mathrm{~b}$ \\
6:00-10:00 p.m. & $0.33(18)$ & $0.5 \pm 0.20 \mathrm{a}$ \\
10:00 p.m.-6:00 a.m. & $0.00(17)$ & $0.0 \pm 0.00 \mathrm{~b}$ \\
& $F_{4,27}=1.62, P=0.20$ & $F_{4,72}=4.66, P=0.0021$ \\
\hline
\end{tabular}

a. Means that share a letter within columns are not significantly different at $\alpha=5 \%$. 
that a berry would become infested did not differ between time periods $\left(F_{4,27}=1.62, P=0.1987\right)$ or among the crop rows where berries were exposed $\left(F_{9,27}=0.46, P=0.8871\right)$ (Table 6).

\section{Discussion}

Overall, the movement of drosophilid species between crop fields and non-crop habitat and their attraction to monitoring traps were related to both time of day and time of year. The diurnal and seasonal behaviors exhibited by $D$. suzukii were similar to those of other drosophilid species present in the system but also different in some important ways.

Other drosophilid species were captured in Malaise traps and at monitoring traps on all sampling dates during the $2 \mathrm{yr}$ of study, whereas $D$. suzukii were not captured until mid-July in both years, which is during the main part of the blackberry harvest season. This difference likely reflects the fact that many of the other drosophilid species captured have very different life histories than $D$. suzukii and utilize a wide variety of natural materials for oviposition, including tree sap, various types of fungi, rotting fruit, and even spittle masses created by spittlebug nymphs (Cladochaeta spp.). One of the most abundant species captured in traps during both years, Drosophila affinis Sturtevant (Diptera: Drosophilidae), was previously reared from decomposing blackberries collected from under wild blackberry bushes in western North Carolina (Miller and Weeks 1964). Females of other species may have been attracted to different oviposition or food resources within the system, such as fungi, tree sap, or plant leaves, that were available throughout or at various times of the season.

Drosophila suzukii appears to have similar daily activity patterns in the wild as other drosophilids (Mitchell and Epling 1951, Miller and Weeks 1964) with most activity occurring during two distinct periods of the day, between 6:00 p.m. and sunset and between sunrise and 10:00 a.m. Interestingly, more females and males of other drosophilid species were caught within monitoring traps, whereas $D$. suzukii females and males were equally likely to be caught on the surface of and within traps. Drosophila suzukii may spend more time on the surface of monitoring traps than other species and maybe oriented to the 
fermenting attractant in these traps for different reasons. Our observations of courting and mating behavior on the surface of monitoring traps suggest that $D$. suzukii may be attracted to traps not only because they are seeking food, but also to interact with conspecifics. Monitoring traps may provide male $D$. suzukii with a suitable substrate on which to perform their courtship dance, which involves both a visual display and substrate-borne vibrations (Fuyama 1979, Mazzoni et al. 2013, Revadi et al. 2015).

More non-D. suzukii drosophilids were caught at monitoring traps placed within crop fields than in traps placed between crop fields and wooded edges, while the opposite pattern was true for $D$. suzukii. Drosophila suzukii has been shown to be more sensitive than $D$. melanogaster to volatiles associated with the fruit-ripening process (Abraham et al. 2015) and to leaf odors (Keesey et al. 2015). As such, the presence of fruit or the plants themselves may have interfered with $D$. suzukii attraction to traps within crop fields. Other species that are primarily attracted to rotting substrates for oviposition or food, such as D. affinis, may have been more likely to detect and get caught in monitoring traps within crop fields. In addition, it is possible that monitoring traps were not equally attractive to $D$. suzukii females at different reproductive stages and that older egg-laying females were more attracted to ripe fruits than to monitoring traps within crop fields (Swoboda-Bhattarai et al. 2017).

Fruit infestation appears to primarily occur during the same time periods when flies were captured in monitoring traps, but some small degree of egg laying appears to occur during the day despite the lack of trap captures. While the likelihood of infestation occurring did not differ between the five daily time periods, significantly higher infestation rates were observed during the evening hours preceding sunset than during the other time periods. Although few studies have looked at the diurnal timing of oviposition behavior in $D$. suzukii, a peak of oviposition activity in cut grapes was observed during the 8:00 p.m.midnight hours of a 16:8 (L:D) h cycle in the laboratory (lights on from 4:30 a.m. to $8: 30$ p.m.), although some eggs were laid throughout the 24-h test period (Lin et al. 2014).

A number of different factors likely drive our observations. Some clearly relate to abiotic conditions. Drosophila species observed in California showed two peaks of daily activity in their natural habitats, one in the morning and another before sunset (Dobzhansky and 
Epling 1944), and it was suggested that temperature, humidity, and light might be factors that limit the periods during which flies visit food sources (Michell and Epling 1951). In a more recent study, it was suggested that the high levels of activity exhibited by $D$. subobscura and Drosophila pseudoobscura Frolova and Astaurov (Diptera: Drosophilidae) near sunrise and sunset could be explained by decreasing sun angles (Noor 1998). At our sampling locations, inflection points in ambient temperature occurred between 7:00-8:00 p.m. and 7:008:00 a.m.; ambient temperatures were several degrees higher within the crop field than along the wooded edge during the day, on average, and vice versa at night (Supp Fig. 1). Because D. suzukii has a limited tolerance for high temperatures (Tochen et al. 2014) and extreme dryness (Eben et al. 2018), these observations could explain why we saw peaks of movement into crop fields during the evening hours and high levels of activity at monitoring traps during the morning and evening hours.

Weather conditions have also been shown to play a role in determining drosophilid activity patterns. Neotropical species of Drosophila were active in the morning and before sunset on clear, warm, and dry days, but were mostly quiescent during the middle part of the day; however, on rainy days the flies were active throughout the day (Pavan et al. 1950). Drosophila suzukii also has limited tolerance for low relative humidity in addition to high temperatures (Tochen et al. 2015), and studies conducted in blueberries showed that $D$. suzukii adults remained active during and after irrigation events (Van Timmeren et al. 2017). We sampled on days with predominately clear conditions, which likely influenced the daily activity patterns we observed.

Crop phenology, or more broadly resource availability, maybe the main driver of some of our observations. Studies have shown that Drosophila species can fly long distances in search of food when necessary (Becher et al. 2010). However, the flight behavior and flight distances of Drosophila are also influenced by the availability of resources in the immediate environment (including food, oviposition substrates, and potential mates) (e.g., Simon et al. 2011) and by the physiological state of individual flies. Due to their highly polyphagous nature, when resources become scarce and/or population densities exceed optimal levels within an available resource, it is thought that $D$. suzukii migrate to more favorable habitats (Mitsui et al. 2010). Our data also suggest that $D$. suzukii might also move between habitats that vary in 
favorability or resource availability on a much finer geographic scale. Drosophila suzukii is known to utilize both blackberry crops and noncrop hosts present along wooded edges (Diepenbrock et al. 2016), while Leach et al. (2019) tracked the movement of $D$. suzukii between cultivated blueberries and honeysuckle in the surrounding habitat. In another study, following weekly treatments of field margin vegetation with a $10 \%$ chicken egg white mark solution, Klick et al. (2016) caught more marked flies and total flies in field margins containing Himalayan blackberry, a known non-crop host, than in field margins without a non-crop host present. Similarly, more flies were caught in crop fields near patches of Himalayan blackberry than near areas without noncrop hosts. Altogether, these findings suggest that field margins containing alternative hosts may result in increased pest pressure within crop fields if $D$. suzukii move from such areas into crop fields, which our Malaise trap captures suggest that they do.

Finally, some of our observations are likely driven primarily by human activity. We conducted our research at commercially managed farms, where insecticides were applied at least weekly in an attempt to prevent $D$. suzukii infestation. Van Timmeren et al. (2017) observed $D$. suzukii adults flying near and landing on highbush blueberry bushes that had been treated with an insecticide, indicating that the insecticides tested did not completely deter fly activity. Although insecticides may not deter $D$. suzukii from entering crop fields, they may prevent some flies from exiting the field, which is a limitation of our experimental design (and may explain why we caught more flies moving into crop fields than out of crop fields overall). Insecticide applications may also impact trap captures within the field, which was observed in both conventional and organic raspberry production systems in California (Hamby et al. 2014). Similar to previous research (Klick et al. 2016, Pelton et al. 2016), our results suggest that growers interested in using traps to monitor for $D$. suzukii should place traps in the area between crop fields and wooded edges or other types of non-crop habitat to maximize the number of flies caught.

In conclusion, some important insights into the movement and activity patterns of drosophilid species in blackberry agroecosystems were gained during this study, that also have important implications for the management of $D$. suzukii in fruit crops. When pesticide treatments are needed, growers should apply insecticides during periods 
of high D. suzukii activity, i.e., late in the day or early in the morning, to increase the probability of adults coming into contact with a lethal dose of insecticide. Applying insecticides during the evening would also increase the likelihood that female $D$. suzukii are exposed to insecticides at times when they are laying eggs. This recommendation has benefits for species other than D. suzukii. Because pollinators are often most active during the midday hours, the adoption of an evening spray schedule for $D$. suzukii, whenever possible, could have additional benefits such as increased pollination for caneberries and other indeterminately-fruiting crops attacked by $D$. suzukii. Understanding the movement and activity patterns of $D$. suzukii will also be useful for potential future management strategies, including attract and kill, mass trapping, and augmentative biological control. As we develop a more complete understanding of what drives $D$. suzukii behavior, this information should be incorporated into predictive tools that model risk and suggest mitigation.

Acknowledgments - Research was funded by the North American Bramble Growers Research Foundation and the North Carolina Agricultural Foundation. We would like to thank the growers who graciously allowed us to conduct experiments on their farms. Tiffany Moore, Lauren Diepenbrock, Linda Della Rosa, Kishor Bhattarai, and Mary and Joe Swoboda assisted with sample collection in the field. Drs. Fred Gould, Nadia Singh, and Jim Walgenbach provided valuable feedback during the planning, implementation, and manuscript preparation phases of this research.

\section{References Cited}

Abraham, J., A. Zhang, S. Angeli, S. Abubeker, C. Michel, Y. Feng, and C. RodriguezSaona. 2015. Behavioral and antennal responses of Drosophila suzukii (Diptera: Drosophilidae) to volatiles from fruit extracts. Environ. Entomol. 44: 356-367.

Asquith, A., and R. H. Messing. 1992. Attraction of Hawaiian ground litter invertebrates to protein hydrolysate bait. Environ. Entomol. 21: 1022-1028.

Atallah, J., L. Teixeira, R. Salazar, G. Zaragoza, and A. Kopp. 2014. The making of a pest: the evolution of a fruit-penetrating ovipositor in Drosophila suzukii and related species. Proc. Biol. Sci. 281: 20132840.

Becher, P. G., M. Bengtsson, B. S. Hansson, and P. Witzgall. 2010. Flying the fly: long-range flight behavior of Drosophila melanogaster to attractive odors. J. Chem. Ecol. 36: 599-607. 
Bellamy, D. E., M. S. Sisterson, and S. S. Walse. 2013. Quantifying host potentials: indexing postharvest fresh fruits for spotted wing Drosophila, Drosophila suzukii. PLoS One 8: e61227.

Bolda, M. P., R. E. Goodhue, and F. G. Zalom. 2010. Spotted wing drosophila: potential economic impact of a newly established pest. Agricultural and Resource Economics Update, University of California, Giannini Foundation. 13: 5-8.

Burrack, H. J., G. E. Fernandez, T. Spivey, and D. A. Kraus. 2013. Variation in selection and utilization of host crops in the field and laboratory by Drosophila suzukii Matsumara (Diptera: Drosophilidae), an invasive frugivore. Pest Manag. Sci. 69: 1173-1180.

Burrack, H. J., M. Asplen, L. Bahder, J. Collins, F. A. Drummond, C. Guédot, R. Isaacs, D. Johnson, A. Blanton, J. C. Lee, et al. 2015. Multistate comparison of attractants for monitoring Drosophila suzukii (Diptera: Drosophilidae) in blueberries and caneberries. Environ. Entomol. 44: 704-712.

Cini, A., C. Ioraitti, and G. Anfora. 2012. A review of the invasion of Drosophila suzukii in Europe and a draft research agenda for integrated pest management. B. Insectology. 65: 149-160.

Cini, A., G. Anfora, L. A. Escudero-Colomar, A. Grassi, U. Santosuosso, G. Seljak, and A. Papini. 2014. Tracking the invasion of the alien fruit pest Drosophila suzukii in Europe. J. Pest Sci. 87: 559-566.

David, J. R., and P. Capy. 1988. Genetic variation of Drosophila melanogaster natural populations. Trends Genet. 4: 106-111.

Depra, M., J. L. Poppe, H. J. Schmitz, D. C. De Toni, and V. L. S. Valente. 2014. The first records of the invasive pest Drosophila suzukii in the South American continent. J. Pest Sci. 87: 379-383.

De Ros, G., S. Conci, T. Pantezzi, and G. Savini. 2015. The economic impact of invasive pest Drosophila suzukii on berry production in the Province of Trento, Italy. J. Berry Res. 5: 89-96.

Diepenbrock, L. M., K. A. Swoboda-Bhattarai, and H. J. Burrack. 2016. Ovipositional preference, fidelity, and fitness of Drosophila suzukii in a co-occurring crop and non-crop host system. J. Pest Sci. 89: 761-769.

Dobzhansky, T., and C. Epling. 1944. Taxonomy, geographic distribution, and ecology of Drosophila pseudoobscura and its relatives. Carnegie Institute of Washington Publication. 554: 1-46.

Eben, A., M. Reifenrath, F. Briem, S. Pink, and H. Vogt. 2018. Response of Drosophila suzukii (Diptera: Drosophilidae) to extreme heat and dryness. Agr. Forest Entomol. 20: 113-121.

Evans, R. K., M. D. Toews, and A. A. Sial. 2017. Diel periodicity of Drosophila suzukii (Diptera: Drosophilidae) under field conditions. PLoS One 12: e0171718.

Ferguson, C. T. J., T. L. O'Neill, N. Audsley, and R. E. Isaac. 2015. The sexually dimorphic behavior of adult Drosophila suzukii: elevated female locomotor activity and loss of siesta is a post-mating response. J. Exp. Biol. 218: 3855-3861. 
Fuyama, Y. 1979. A visual stimulus in the courtship of Drosophila suzukii. Experientia. 35: 1327-1328.

Hamby, K. A., R. S. Kwok, F. G. Zalom, and J. C. Chiu. 2013. Integrating circadian activity and gene expression profiles to predict chronotoxicity of Drosophila suzukii response to insecticides. PLoS One 8: e68472.

Hamby, K. A., M. P. Bolda, M. E. Sheehan, and F. G. Zalom. 2014. Seasonal monitoring for Drosophila suzukii (Diptera: Drosophilidae) in California commercial raspberries. Environ. Entomol. 43: 1008-1018.

Hauser, M. 2011. A historic account of the invasion of Drosophila suzukii (Matsumura) (Diptera: Drosophilidae) in the continental United States, with remarks on their identification. Pest Manag. Sci. 67: 1352-1357.

Hoffmann, A. A., and P. A. Parsons. 1984. Olfactory response and resource utilization in Drosophila: interspecific comparisons. Biol. J. Linn. Soc. 22: 43-53.

loriatti, C., R. Guzzon, G. Anfora, F. Ghidoni, V. Mazzoni, T. R. Villegas, D. T. Dalton, and V. M. Walton. 2018. Drosophila suzukii (Diptera: Drosophilidae) Contributes to the Development of Sour Rot in Grape. J. Econ. Entomol. 111: 283-292.

Kaneshiro, K. Y. 1983. Drosophila (Sophophora) suzukii (Matsumura). Notes and exhibitions. P. Hawaii Entomol. Soc. 24: 179.

Kanzawa, T. 1935. Research into the fruit-fly Drosophila suzukii Matsumura (Preliminary Report). Yamanashi Prefecture Agricultural Experiment Station Report, Kofu, Japan.

Kanzawa, T. 1939. Studies on Drosophila suzukii Mats. Yamanshi Prefecture Agricultural Experimental Station Report, Kofu, Japan.

Keesey, I. W., M. Knaden, and B. S. Hansson. 2015. Olfactory specialization in Drosophila suzukii supports an ecological shift in host preference from rotten to fresh fruit. J. Chem. Ecol. 41: 121-128.

Kirkpatrick, D. M., L. J. Gut, and J. R. Miller. 2018. Estimating monitoring trap plume reach and trapping area for Drosophila suzukii (Diptera: Drosophilidae) in Michigan Tart Cherry. J. Econ. Entomol. 111: 1285-1289.

Klick, J., W. Q. Yang, V. M. Walton, D. T. Dalton, J. R. Hagler, A. J. Dreves, J. C. Lee, and D. J. Bruck. 2016. Distribution and activity of Drosophila suzukii in cultivated raspberry and surrounding vegetation. J. Appl. Entomol. 140: 37-46.

Leach, H., J. R. Hagler, S. A. Machtley, and R. Isaacs. 2019. Spotted wing drosophila (Drosophila suzukii) utilization and dispersal from the wild host Asian bush honeysuckle (Lonicera spp.). Agr. Forest. Entomol. 21: 149-158.

Leblanc, L., P. M. O'Grady, D. Rubinoff, and S. L. Montgomery. 2009. New immigrant Drosophilidae in Hawaii, and a checklist of the established immigrant species. P. Hawaii Entomol. Soc. 41: 121-127.

Lee, J. C., D. J. Bruck, H. Curry, D. Edwards, D. R. Haviland, R. A. Van Steenwyk, and B. M. Yorgey. 2011. The susceptibility of small fruits and cherries to the spotted-wing drosophila, Drosophila suzukii. Pest Manag. Sci. 67: 1358-1367.

Lee, J. C., D. T. Dalton, K. A. Swoboda-Bhattarai, D. J. Bruck, H. J. Burrack, B. C. Strik, J. M. Woltz, and V. M. Walton. 2016. Characterization and manipulation of fruit susceptibility to Drosophila suzukii. J. Pest Sci. 89: 771-780. 
Lin, Q-C., Y-F. Zhai, C-G. Zhou, L-L. Li, Q-Y. Zhuang, X-Y. Zhang, F. G. Zalom, and Y. Yu. 2014. Behavioral rhythms of Drosophila suzukii and Drosophila melanogaster. Fla. Entomol. 97: 1424-1433.

Markow, T. A., and P. M. O'Grady. 2006. Drosophila: a guide to species identification and use. Academic Press, London, United Kingdom.

Markow, T. A., and P. O'Grady. 2008. Reproductive ecology of Drosophila. Funct. Ecol. 22: 747-759.

Mazzoni, V., G. Anfora, and M. Virant-Doberlet. 2013. Substrate vibrations during courtship in three Drosophila species. PLoS One 8: e80708.

Michell, D. F., and C. Epling. 1951. The diurnal periodicity of Drosophila pseudoobscura in southern California. Ecology 32: 696-708.

Miller, D. D., and L. Weeks. 1964. Drosophila collections near the Blue Ridge of southwestern North Carolina. Am. Midl. Nat. 72: 93-114.

Miller, M. E., S. A. Marshall, and D. A. Grimaldi. 2017. A review of the species of Drosophila (Diptera: Drosophilidae) and genera of Drosophilidae of Northeastern North America. Can. J. Arthropod Identification. 31: 1-282.

Mitsui, H., K. Beppu, and M. T. Kimura. 2010. Seasonal life cycles and resource uses of flower- and fruit-feeding drosophilid flies (Diptera: Drosophilidae) in central Japan. Entomol. Sci. 13: 60-67.

Noor, M. A. F. 1998. Diurnal activity patterns of Drosophila subobscura and D. pseudoobscura in sympatric populations. Am. Midl. Nat. 140: 34-41.

Ometto, L., A. Cestaro, S. Ramasamy, A. Grassi, S. Revadi, S. Siozios, M. Moretto, P. Fontana, C. Varotto, D. Pisani, et al. 2013. Linking genomics and ecology to investigate the complex evolution of an invasive Drosophila pest. Genome Biol. Evol. 5: 745-757.

Pascual, M., M. P. Chapuis, F. Mestres, J. Balanyà, R. B. Huey, G. W. Gilchrist, L. Serra, and A. Estoup. 2007. Introduction history of Drosophila subobscura in the New World: a microsatellite-based survey using ABC methods. Mol. Ecol. 16: 3069-3083.

Pavan, C., T. Dobzhansky, and H. Burla. 1950. Diurnal behavior of some Neotropical species of Drosophila. Ecology 31: 36-43.

Revadi, S., S. Lebreton, P. Witzgall, G. Anfora, T. Dekker, and P. G. Becher. 2015. Sexual Behavior of Drosophila suzukii. Insects. 6: 183-196.

Simon, J. C., W. B. Dickson, and M. H. Dickinson. 2011. Prior mating experience modulates the dispersal of Drosophila in males more than in females. Behav. Genet. 41: 754-767.

Swoboda-Bhattarai, K. A., and H. J. Burrack. 2016. Drosophila suzukii infestation in ripe and ripening caneberries. Acta Hortic. 1133: 419-430.

Swoboda-Bhattarai, K. A., D. R. McPhie, and H. J. Burrack. 2017. Reproductive Status of Drosophila suzukii (Diptera: Drosophilidae) Females Influences Attraction to Fermentation-Based Baits and Ripe Fruits. J. Econ. Entomol. 110: 1648-1652.

Tochen, S., D. T. Dalton, N. Wiman, C. Hamm, P. W. Shearer, and V. M. Walton. 2014. Temperature-related development and population parameters for 
Drosophila suzukii (Diptera: Drosophilidae) on cherry and blueberry. Environ. Entomol. 43: 501-510.

Tochen, S., J. M. Woltz, D. T. Dalton, J. C. Lee, N. G. Wiman, and V. M. Walton. 2015. Humidity affects populations of Drosophila suzukii (Diptera: Drosophilidae) in blueberry. J. Appl. Entomol. 140: 47-57.

Tonina, L., N. Mori, M. Sancassani, P. Dall'Ara, and L. Marini. 2018. Spillover of Drosophila suzukii between noncrop and crop areas: implications for pest management. Agr. Forest Entomol. 20: 575-581.

Van Timmeren, S., L. Horejsi, S. Larson, K. Spink, P. Fanning, and R. Isaacs. 2017. Diurnal activity of Drosophila suzukii (Diptera: Drosophilidae) in highbush blueberry and behavioral response to irrigation and application of insecticides. Environ. Entomol. 46: 1106-1114.

Walsh, D. B., M. P. Bolda, R. E. Goodhue, A. J. Dreves, J. Lee, D. J. Bruck, V. M. Walton, S. D. O'Neal, and F. G. Zalom. 2011. Drosophila suzukii (Diptera: Drosophilidae): invasive pest of ripening soft fruit expanding its geographic range and damage potential. J. Integ. Pest Manag. 2: G1-G7. 